\title{
INVESTIGATION OF THE APPLICATION OF A NEW METHOD OF EXTRACTION INTENSIFICATION OF PECTIN SUBSTANCES FROM A BEET PULP
}

\author{
Gregoriy Deynichenko \\ Department of Equipment Food and Hospitality Industry named after M. Belyaeva \\ Kharkiv State University of Food Technology and Trade \\ 333 Klochkivska str., Kharkiv, Ukraine, 61051 \\ deinychenkogv@ukr.net \\ Vasyl Guzenko \\ Department of Equipment Food and Hospitality Industry named after M. Belyaeva \\ Kharkiv State University of Food Technology and Trade \\ 333 Klochkivska str., Kharkiv, Ukraine, 61051 \\ zasada.avas.3@gmail.com \\ Dmytro Dmytrevskyi \\ Department of Equipment Food and Hospitality Industry named after M. Belyaeva \\ Kharkiv State University of Food Technology and Trade \\ 333 Klochkivska str., Kharkiv, Ukraine, 61051 \\ dmitrevskyidv@gmail.com

\section{Vitalii Chervonyi} \\ Department of Equipment Food and Hospitality Industry named after M. Belyaeva \\ Kharkiv State University of Food Technology and Trade \\ 333 Klochkivska str., Kharkiv, Ukraine, 61051 \\ chervonyi.v@gmail.com
}

Tatiana Kolisnichenko

Department of Food Technology

Oles Honchar Dnipro National University

72 Gagarina str., Dnipro, Ukraine, 49010

ktatyna1407@gmail.com

\section{Aleksandr Omelchenko}

Department of general engineering disciplines and equipment

Donetsk National University of Economics and Trade named after Mykhailo Tugan-Baranovsky 16 Tramvayna str., Kryvyi Rih, Ukraine, 50005 omelchenko@donnuet.edu.ua

\section{Olga Melnik}

Department of general engineering disciplines and equipment

Donetsk National University of Economics and Trade named after Mykhailo Tugan-Baranovsky 16 Tramvayna str., Kryvyi Rih, Ukraine, 50005

melnik@donnuet.edu.ua

Olga Simakova

Department of general engineering disciplines and equipment

Donetsk National University of Economics and Trade named after Mykhailo Tugan-Baranovsky 16 Tramvayna str., Kryvyi Rih, Ukraine, 50005

Simakova@donnuet.edu.ua 


\title{
Radion Nykyforov \\ Department of general engineering disciplines and equipment \\ Donetsk National University of Economics and Trade named after Mykhailo Tugan-Baranovsky \\ 16 Tramvayna str., Kryvyi Rih, Ukraine, 50005 \\ Nykyforov@donnuet.edu.ua
}

\begin{abstract}
The aim of research is studying a new method for intensifying extraction of pectin substances during acid extraction of pectin-containing raw materials. The description of the experimental setup and the procedure for processing the results of the investigation of the application of a new method for intensifying the beet pulp extraction are described. The results of experimental studies on the application of a new combined mixing element for intensifying the extraction of pectin-containing raw materials (beet pulp) and its effect on quantitative and qualitative output characteristics are presented. Mathematical models are constructed on the basis of regression equations of the full factorial experiment with the use of a new method of intensifying the extraction process to select input technological parameters for the extraction of pectin substances from pectin-containing raw materials. The rational operating parameters of the process of extraction of pectin substances with the use of a new combinable stirring element are determined. Such working parameters are: the process duration is $1 . . .1 .1$, the temperature of the working medium is $60 \ldots 70^{\circ} \mathrm{C}$, and the hydromodule is $8 \ldots 10$. The research results can be used to study other technological parameters of the extraction process of pectin substances, as well as to develop a technological line for the production of pectin products.

Keywords: pectin-containing raw materials, acid extraction process, pectin substances, stirring element.

(C) Gregoriy Deynichenko, Vasyl Guzenko, Dmytro Dmytrevskyi, Vitalii Chervonyi, Tatiana Kolisnichenko, Aleksandr Omelchenko,

\section{Introduction}

One of the possible ways of solving the problem of saturation of the consumer market with pectin products (pectin extracts, their liquid and dry concentrates) is the realization of the technology for obtaining these pectin products. Typical features of these technologies can be: the possibility of using various pectin-containing raw materials (sunflower baskets, apple and beet pulp), easy transformation in the transition from one type of product to another, high intensity, ecological purity due to the complexity of processing and elimination in a number of options for the utilization of chemical reagents. An important element of beet pulp as a pectin-containing raw material is polygalacturonan, thanks to which, in a purified form, pectin $h$ as a number of valuable biological properties, first of all - the ability to create complexes with heavy and radioactive metals, phenols, amines and the ability to remove them from the body [1, 2]. As a final product based on pectin substances (PS) contained in pectin-containing raw materials, it is possible to produce various preparations of therapeutic and prophylactic action in the form of polysaccharide complexes that can be used alone or as part of food products - dairy, confectionery and bakery products [3].

The main process of the general technology for the production of pectin products is the PS extraction from plant raw materials. There are known developments to improve this process by applying chemical and physico-mechanical methods of influencing plant raw materials $[4,5]$.

The most common way of extracting pectin-containing raw materials is PS extraction with the use of inorganic and organic acids (hydrochloric, nitric, acetic, lactic, citric, etc.) [6-8]. For this, corrosion-resistant equipment is used (especially if the process involves a high temperature). This method is one of the most common when extracting PS [9].

It should be noted that the use of the above reagents is unsafe, and also takes a long time. This is especially true for multi-stage extraction processes (for example, the production of apple pectin extract, where the extraction process lasts 3-4 hours) [10]. 
To intensify the extraction process, various types of turbulence are used. These include stirring the solution with a variety of agitators [11]. One of the modern ways of extracting pectin-containing raw materials is the use of the phenomenon of cavitation for $30 \ldots 35$ minutes at a temperature of $70{ }^{\circ} \mathrm{C}$, a cavitation index of $1.1, \mathrm{pH}=1.5$, a hydromodule of 1:7. The use of such intensification means accelerates the extraction process in 3...4 times, but the quality of the products remains unknown. But at the same time, the cavitation equipment for carrying out the extraction process has a complex design, and its manufacture requires high accuracy [12].

Analyzing the above, it can be concluded that for effective extraction of pectin substances, the best way is to use combined extraction process methods using acidic reagents and mixing equipment. Therefore, a study of the extraction of pectin-containing raw materials using safe reagents and new mixing devices is relevant.

The aim of research is studying the application of a new method for intensifying the extraction of pectin substances with the definition of rational parameters of the extraction process from pectin-containing raw materials (beet pulp). This will improve the process and apply this method to investigate the extraction of other pectin-containing raw materials.

To achieve this aim, it is necessary to solve the following tasks:

- describe the technical support and mathematical description of the study of the method for intensifying the extraction of pectin-containing raw materials;

- determine the factors that affect the intensification of the extraction process of pectin substances with the use of mixing devices;

- based on the research results, determine the rational parameters for extraction of pectin-containing raw materials (beet pulp) using a combined mixing element.

\section{Materials and Methods}

In order to intensify the extraction of pectin substances from the pectin-containing raw material, a method using a combined agitator is proposed. Acceleration of the extraction process of pectin substances is due to the uniform distribution of particles of pectin-containing raw materials along the entire volume of the technological capacity, which is caused by turbulence (active circulation) of the processed medium flows.

As a raw material, crushed fresh and dried sugar beet pulp was used as a secondary raw material of sugar production, citric acid powder, sodium bicarbonate (baking soda) powder. And also a $40 \%$ solution of sodium hydroxide and a hydrochloric acid concentrate for the precipitation of pectin substances. An experimental device is developed to study the extraction of pectin-containing raw materials with a lattice stirrer and a combine stirring element. Methods of mathematical processing of research results using modern computer programs are used.

\section{1. Experimental procedures}

To study the extraction process, an experimental device is developed (Fig. 1, 2). It works as follows. The container with the heated coolant (water) 6, in which the working container 15 is located, is covered with an extractant and fresh raw material by the lid 3, after which the extraction process is carried out. If dry beet pulp is used, it is preliminarily covered in a container 15 and filled with water at room temperature, which is heated by the heating device 8 to a temperature of $50{ }^{\circ} \mathrm{C}$. First, the washing and swelling processes are carried out using the grate and combined stirring element 14 . The washed beet pulp is then wrung out through a filter cloth, poured with a solution of citric acid, with a $\mathrm{pH}$ value of 1.5...1.7, and an extraction process is carried out with constant stirring in flow 1,5-2 hours.

In the developed experimental device with a combined stirring element, the process of PS extraction from sugar beet pulp has several joint processes: dispersion, hydrolysis, pectin extraction, homogenization of the treated medium. 


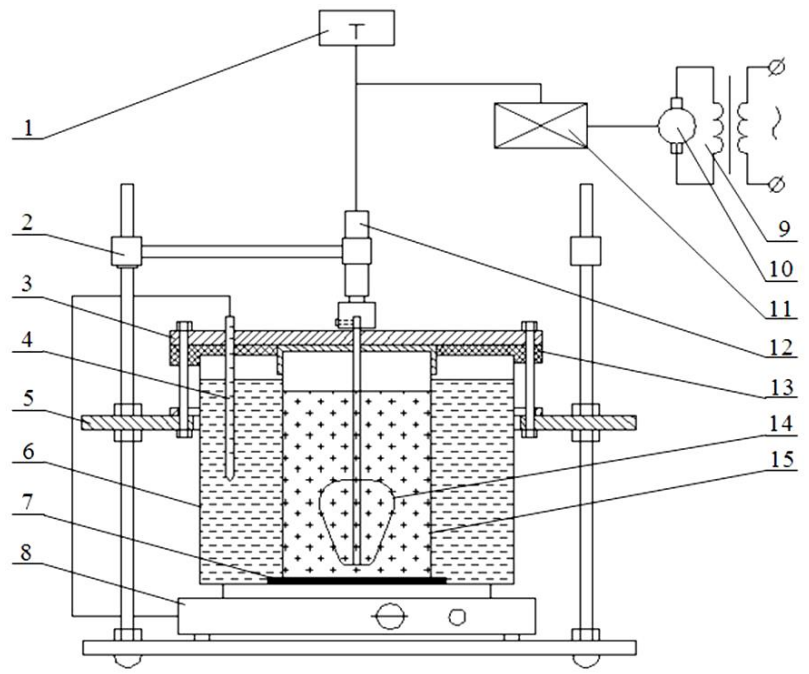

Fig. 1. Schematic diagram of the experimental device for studying the PS extraction process: 1 - tachometer; 2 - chuck holder; 3 - lid; 4 - thermal signaling device; 5 - bed; 6 - container with coolant; 7 - base plate; 8 - heating device; 9 - autotransformer; 10 - electric motor; 11 - reducer; 12 - chuck catch; 13 - insulation; 14 - stirring element; 15 - working tank

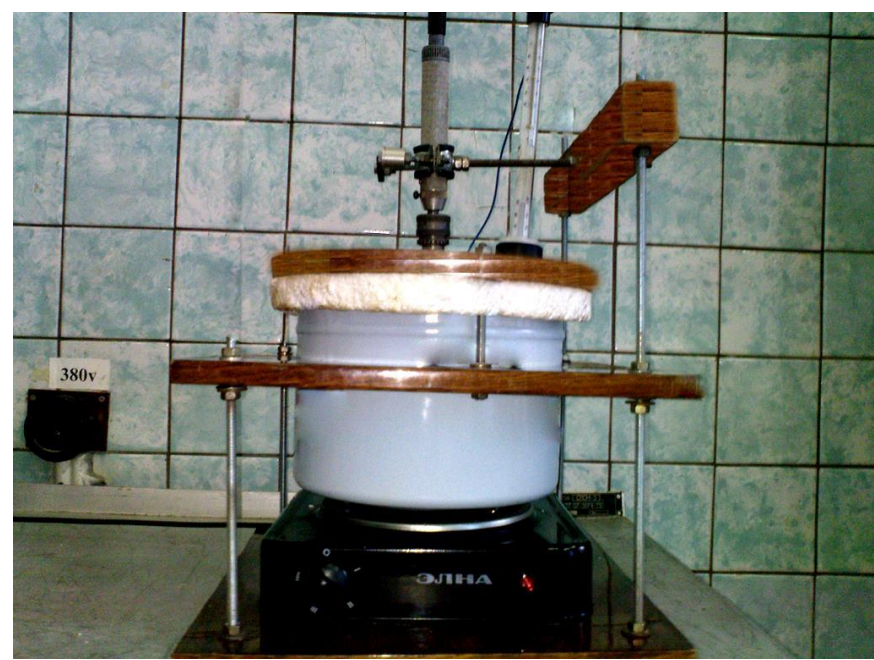

Fig. 2. Appearance of the extraction unit

\section{2. Simulation of the extraction process of pectin substances}

To determine the parameters of the PS extraction flow, a mathematical model is proposed, based on the regression equations according the methods for planning a multifactor experiment. It allows to provide an adequate description of the processes that take place during the extraction of pectin-containing raw materials. It also makes it possible to determine the optimal conditions for PS hydrolysis-extraction, taking into account the different molecular weight parameters and complexing ability of the obtained pectin extracts [13].

For the study, the following main process indicators are selected: $\mathrm{t}-$ extraction temperature, ${ }^{\circ} \mathrm{C} ; \tau$ - extraction duration, $\mathrm{s}^{2} ; \mathrm{q}$ - hydromodule ratio of solid and liquid phases.

For these parameters, the levels and variation intervals are set, which are listed in Table 1.

According to the mathematical model of the PS extraction process, the least squares method is used to find the regression equation describing the surface of the response function in the factor space and has the following form:

$$
y=b_{0}+\sum_{i=1}^{n} b_{i} x_{i}+\sum_{\substack{i=1 \\ j=1}}^{n} b_{i j} x_{i} x_{j},
$$


where $b_{0}-$ absolute term of the regression equation; $b_{i}-$ linear effects; $x_{i}, x_{j}-$ independent variables; $b_{i, j}$ - effects of pair interaction; $n-$ the number of experiment

Table 1

Levels and intervals of variation

\begin{tabular}{ccccc}
\hline Experimental conditions & Designations & \multicolumn{2}{c}{ Influence parameters } \\
\hline Main level & $\mathrm{x}_{\mathrm{i} 0}$ & 60 & $\boldsymbol{\tau}, \mathbf{h}$ & $\mathbf{q}$ \\
\hline Variation interval & $\Delta \mathrm{x}_{\mathrm{i}}$ & 20 & 0,6 & 7 \\
Top level & $\mathrm{x}_{\text {imax }}$ & 80 & 0,4 & 3 \\
Lower level & $\mathrm{x}_{\text {imin }}$ & 40 & 0,2 & 4
\end{tabular}

To prepare the pectin extract, $50 \mathrm{~g}$ of fresh beet pulp was loaded into an experimental device, the water was poured with water heated to $40 \ldots 50{ }^{\circ} \mathrm{C}$ to carry out the washing-swelling process of the pulp from pollutants. Then, a saturated solution of citric acid with predetermined $\mathrm{pH}$ values of 1.5...1.7 was added to the working tank of the experimental device to the pressed swollen pulp. After extraction, the obtained extract was separated from the solid phase, cooled and PS was precipitated by the bulk method [14]. Molecular weight was determined by viscometric method, complexing ability - by titration method, gel-forming ability - by valent method [15]. During the study all experiments were conducted 3 times. The results were statistically processed by the method of least squares.

Determination of the coefficients of nonlinear regression equations was carried out by constructing a planning matrix, where the number of studies and the limits of the change in factors were determined. As a result of the studies and regression analysis, regression equations are obtained, which are represented in the natural way as follows.

The PS concentration in the extracts obtained from fresh beet pulp with the use of a lattice stirring element:

$$
\begin{aligned}
\mathrm{C}_{\mathrm{PS}}= & -0,171+0,028 \mathrm{t}-0,146 \tau-0,076 \mathrm{q}-2,469 \cdot 10^{-4} \mathrm{t}^{2}+0,25 \tau^{2}+ \\
& +6,111 \cdot 10^{-3} \mathrm{q}^{2}-7,812 \cdot 10^{-4} \mathrm{t} \cdot \tau+1,042 \cdot 10^{-4} \mathrm{t} \cdot \mathrm{q}+0,027 \tau \cdot \mathrm{q}
\end{aligned}
$$

- PS concentration for the combined stirring element:

$$
\begin{aligned}
\mathrm{C}_{\mathrm{PS}}^{\mathrm{T}}=-0,414+0,017 \mathrm{t}-0,448 \tau-0,083 \cdot 10^{-3} \mathrm{q}-1,153 \cdot 10^{-4} \mathrm{t}^{2}+0,453 \tau^{2}+ \\
\\
+6,944 \cdot 10^{-3} \mathrm{q}^{2}-1,875 \cdot 10^{-3} \mathrm{t} \cdot \tau-8,333 \cdot 10^{-5} \mathrm{t} \cdot \mathrm{q}+0,054 \tau \cdot \mathrm{q}
\end{aligned}
$$

- molecular mass:

$$
\begin{aligned}
\mathrm{MM}= & -8,575 \cdot 10^{3}+616,958 \mathrm{t}+73,958 \tau+952,083 \mathrm{q}-4,827 \mathrm{t}^{2}-273,438 \tau^{2}- \\
& -273,438 \tau^{2}-32,083 \mathrm{q}^{2}+52,344 \mathrm{t} \cdot \tau-7,021 \mathrm{t} \cdot \mathrm{q}-164,583 \tau \cdot \mathrm{q}
\end{aligned}
$$

- complexing ability:

$$
\begin{gathered}
\mathrm{CA}=3,279-0,036 \mathrm{t}+0,392 \tau-0,017 \mathrm{q}-1,5 \cdot 10^{-4} \mathrm{t}^{2}-0,5 \tau^{2}-0,042 \mathrm{q}^{2}+ \\
+0,016 \mathrm{t} \cdot \tau+0,011 \mathrm{t} \cdot \mathrm{q}-0,042 \tau \cdot \mathrm{q}
\end{gathered}
$$

- gel-forming ability:

$$
\begin{gathered}
\mathrm{GA}=-125,854+5,107 \mathrm{t}+89,375 \tau+8,708 \mathrm{q}-0,036 \mathrm{t}^{2}-67,187 \tau^{2}- \\
-0,417 \mathrm{q}^{2}+0,203 \mathrm{t} \cdot \tau+0,023 \mathrm{t} \cdot \mathrm{q}+0,325 \tau \cdot \mathrm{q} .
\end{gathered}
$$


The above equations were obtained by mathematical processing of the complete factorial experiment data using the Excel 2007 table processor and the problem-oriented Mathcad 15 computation package.

\section{Results}

An important factor significantly influencing the extraction of pectin substances from beet pulp with the use of a new combinable stirring element is the temperature of the process medium. Therefore, the influence of the temperature parameters of the acid extraction process on the change in the concentration of pectin substances in the extractant was investigated. Therefore, the influence of the temperature of the acid extraction process on the change in the concentration of pectin substances in solution for both types of raw materials, which is shown in Fig. 3.

From Fig. 3, it can be seen that the data of the dependence of the PS extraction process with the use of lattice and combined mixing elements have the same nonlinear character. An intensive increase in the concentration of pectin substances in the acid solution occurs with an increase in the temperature of the process medium to $60^{\circ} \mathrm{C}$, after which the growth in the concentration of pectin substances in the extractant slows down considerably. With further extraction, PS concentration in the extractant begins to decrease for both types of raw materials.

Therefore, rational values of the temperature of the process of extracting pectin-containing raw materials should be considered as $60 \ldots 65^{\circ} \mathrm{C}$, since they are the most conducive to increasing the PS concentration in the extractant.

As a result of the mathematical modeling, the conditions for carrying out the extraction of pectin-containing raw materials using a combined stirring element were determined. This made it possible to determine the rational parameters of the output characteristics (molecular mass, complexing and gel-forming ability), as well as possible maximum values of these characteristics under the condition of optimal process parameters.

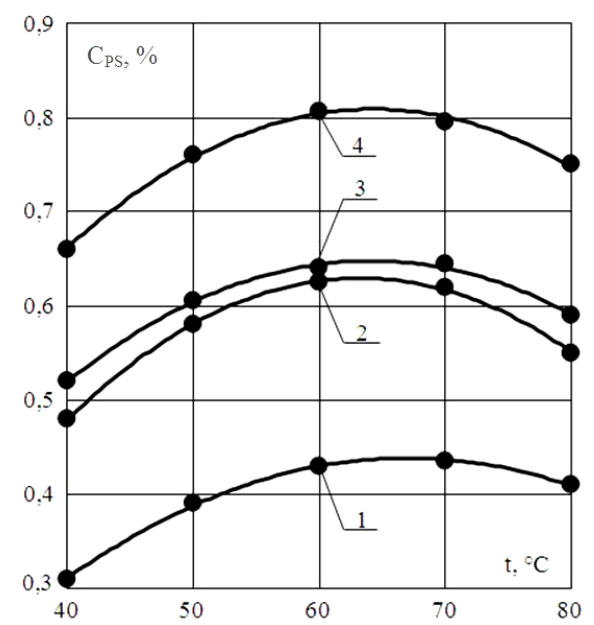

Fig. 3. Dependence of the change in the PS concentration on the extraction temperature at $\tau=1 \cdot 60^{2} \mathrm{~s} ; \mathrm{q}=10: 1,3$ - dry beet pulp; 2, 4 - fresh beet pulp; 1, 2 - lattice stirrer; 3, 4 - combined mixing element

Optimization of technological regimes of extraction of pectin-containing raw materials using a combined mixing element made it possible to construct three-dimensional graphical dependencies characterizing this process (Fig. 4, 5).

The data of experimental studies of technological regimes using a mathematical model on the dependencies make it possible to select rational technological parameters for the extraction of dry pectin-containing raw materials using a combined mixing element. The maximum efficiency of the extraction of pectin substances from pectin-containing raw materials using a combined stirring element is achieved with the process duration values - (1.0..1.1) $60^{2}$ and process temperatures $-60 \ldots 70{ }^{\circ} \mathrm{C}$. 


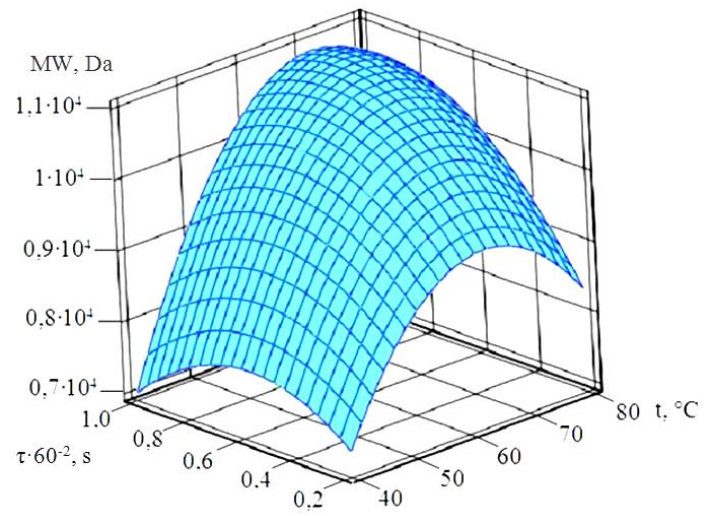

Fig. 4. Mathematical model for the selection of parameters for the extraction of dry pectin-containing raw materials by molecular weight

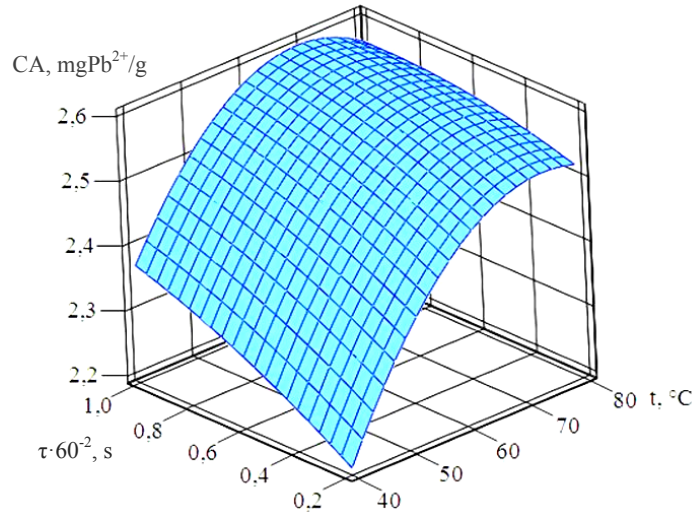

Fig. 5. Mathematical model of the selection of parameters for the extraction of dry pectin-containing raw materials by complexing ability

Comparative analysis of the calculated and experimental characteristics of the obtained UV concentrates showed some similarity of the calculated and input characteristics of the process (temperature, duration and hydromodule) for two types of raw materials (beet pulp).

Analysis of the obtained data of mathematical modeling (Fig. 4) indicates that with increasing the process temperature from $20^{\circ} \mathrm{C}$ to $60{ }^{\circ} \mathrm{C}$, the PS molecular weight is increased to a maximum value of $\mathrm{MM}=1.86 \times 104 \mathrm{Da}$. With further increase in the temperature of the process to $80{ }^{\circ} \mathrm{C}$, the PS molecular mass begins to decrease sharply, which can be explained by a decrease in the PS physico-mechanical properties in the extract under the influence of high temperatures.

In the case of an increase in the duration of the extraction process, it can be observed that the PS molecular weight increases intensively to durations $(0.9 \ldots 1.0) \cdot 60^{2}$ using the intensification method, after which the value of its increase slows down. Obviously, this is explained by the hydrodynamics of the process under the influence of a combined stirring element, which simultaneously mixes and disperses the pectin-containing raw material.

The same changes are observed in the case of the determination of the PS complexing ability (Fig. 5), which values increase in proportion to the increase in temperature and the duration of the extraction of dry pectin-containing raw material $\mathrm{CA}_{\max }=2.5 \ldots 2.6 \mathrm{mg} \mathrm{Pb} \mathrm{Pb}^{2+/ \mathrm{g}}$.

The analysis of the regression equations obtained in the mathematical model of the complete factorial experiment has shown that the values of the output characteristics (molecular mass, complexing and gel-forming ability) of PS depend on the duration of the extraction process, the temperature of the process medium and the hydromodule. But most of all, these characteristics increase with increasing temperature of the extraction process of pectin-containing raw materials and with continuous mixing of raw materials. 


\section{Conclusions}

The information is received that the use of mixing devices is promising from the point of view of improving the extraction process of pectin-containing raw materials (beet pulp) in order to obtain high quantitative and qualitative characteristics of pectin extracts, while the issue of creating new methods of intensifying PS extraction is still topical.

The carried out researches are continuation of researches on perfection of extraction processes of useful substances from raw materials with development of new methods of an intensification of extraction process. The obtained results can be used for studying other technological parameters in the extraction process of pectin-containing raw materials, as well as for improving the equipment of production lines for production of various pectin products.

\section{References}

[1] Concha, J., Weinstein, C., Zúñiga, M. E. (2013). Production of pectic extracts from sugar beet pulp with antiproliferative activity on a breast cancer cell line. Frontiers of Chemical Science and Engineering, 7(4), 482-489. doi: https://doi.org/10.1007/s11705-013-1342-5

[2] Yapo, B. M. (2011). Pectic substances: From simple pectic polysaccharides to complex pectins A new hypothetical model. Carbohydrate Polymers, 86 (2), 373-385. doi: https://doi.org/10.1016/j.carbpol. 2011.05.065

[3] Panchami, P. S., Gunasekaran, S. (2017). Extraction and Characterization of Pectin from Fruit Waste. International Journal of Current Microbiology and Applied Sciences, 6 (8), 943-948. doi: https:// doi.org/10.20546/ijcmas.2017.608.116

[4] Golyibin, V., Matvienko, A., Fedoruk, V., Murach, D. (2015). A method of producing pectin and dietary fibers using electrochemically activated water. Vestnik Voronezhskogo gosudarstvennogo universiteta inzhenernyh tehnologij, 3, 161-165.

[5] Round, A. N., Rigby, N. M., MacDougall, A. J., Morris, V. J. (2010). A new view of pectin structure revealed by acid hydrolysis and atomic force microscopy. Carbohydrate Research, 345(4), 487-497. doi: https://doi.org/10.1016/j.carres.2009.12.019

[6] Liew, S. Q., Chin, N. L., \& Yusof, Y. A. (2014). Extraction and Characterization of Pectin from Passion Fruit Peels. Agriculture and Agricultural Science Procedia, 2, 231-236. doi: https://doi.org/10.1016/ j.aaspro.2014.11.033

[7] Zouambia, Y., Youcef Ettoumi, K., Krea, M., \& Moulai-Mostefa, N. (2017). A new approach for pectin extraction: Electromagnetic induction heating. Arabian Journal of Chemistry, 10 (4), 480-487. doi:10.1016/j.arabjc.2014.11.011

[8] Deynichenko, G., Afukova, N., Maznjak, Z., Guzenko, V. (2014). Development of equipment for the research quantitative and qualitative characteristics of pectin concentrates. Technology Audit and Production Reserves, 3(5(17)), 11-14. doi: https://doi.org/10.15587/2312-8372.2014.25353

[9] Harholt, J., Suttangkakul, A., Scheller, H. (2010). Biosynthessis of pectin. Plant Physiology, 153, $384-395$

[10] Kyselov, D., Hrynyk, I. (2017). Adaptatsiia parametriv ekstraktsii pektynu z yabluchnoi syrovyny z vykorystanniam burshtynovoi kysloty. Naukovyi visnyk NUBIP Ukrainy, 269, 208-214.

[11] Kaya, M., Sousa, A. G., Crépeau, M.-J., Sørensen, S. O., Ralet, M.-C. (2014). Characterization of citrus pectin samples extracted under different conditions: influence of acid type and $\mathrm{pH}$ of extraction. Annals of Botany, 114(6), 1319-1326. doi: https://doi.org/10.1093/aob/mcu150

[12] hen, H., Fu, X., Luo, Z. (2015). Properties and extraction of pectin-enriched materials from sugar beet pulp by ultrasonic-assisted treatment combined with subcritical water. Food Chemistry, 168, 302-310. doi: https://doi.org/10.1016/j.foodchem.2014.07.078

[13] Ostapchuk, M., Stankevy’ch, G. (2006). Matematy’chne modelyuvannya na EOM. Odesa, Druk, 313.

[14] Voragen, A. G. J., Coenen, G.-J., Verhoef, R. P., Schols, H. A. (2009). Pectin, a versatile polysaccharide present in plant cell walls. Structural Chemistry, 20 (2), 263-275. doi: https://doi.org/10.1007/ s11224-009-9442-z

[15] Miglio, C., Chiavaro, E., Visconti, A., Fogliano, V., Pellegrini, N. (2008). Effects of Different Cooking Methods on Nutritional and Physicochemical Characteristics of Selected Vegetables. Journal of Agricultural and Food Chemistry, 56 (1), 139-147. doi: https://oi.org/10.1021/jf072304b 